\title{
Treating of Rayon-flocked Fabric by Atmospheric Pressure Plasma
}

\author{
Chi-wai KAN $^{1 *}$, Chi-ho KWONG ${ }^{1}$, Sun-pui NG $^{2}$, Chun-wah Marcus YUEN ${ }^{1}$ \\ ${ }^{1}$ Institute of Textiles and Clothing, Hong Kong Polytechnic University, Hung Hom, Kowloon, Hong Kong \\ ${ }^{2}$ Hong Kong Community College, Hong Kong Polytechnic University, Hung Hom, Kowloon, Hong Kong \\ cross $^{\text {ref }}$ http://dx.doi.org/10.5755/j01.ms.22.3.9787
}

Received 06 February 2015; accepted 15 July 2015

\begin{abstract}
This study investigates hydrophobisation of the surface of rayon-flocked fabric by means of atmospheric pressure plasma (APP) treatment with tetramethylsilane (TMS). Plasma deposition of TMS is regarded as an effective, single-step low pollution method. A detailed study of the process parameters was conducted. A highly hydrophobic surface was successfully fabricated on rayon-flocked fabric and the hydrophobic surface was found to have good stain resistance to coffee and milk tea.

Keywords: atmospheric pressure plasma, hydrophobic, rayon-flocked fabric, stain.
\end{abstract}

\section{INTRODUCTION}

Much efforts have been made to find ways of enhancing surface hydrophobicity of synthetic textile materials. Optical transparent superhydrophobic, silica based surface film was prepared by introducing nano-scale rough surface [1]. Super hydrophobic surface can be obtained by preparing aligned carbon nanotubes coated by zinc oxide thin film [2]. Superhydrophobicity of nylon flock fabric was successfully fabricated by grafting with poly(acrylic acid) and 1H-1H-perfluorooctyl-amine [3]. In addition, hydrophobic coating can be fabricated by $\mathrm{CF}_{4}$ plasma treatment [4].

Because of its unique ability to fabricate hydrophobic thin film on surface, plasma treatment of polymer surface can be an effective way [5]. Atmospheric pressure plasma (APP) treatment overcomes the disadvantages of low pressure plasma treatment (high cost and cumbersome process) in terms of its integration into a continuous production process [6].

Recently, imitation leather is increasingly being used as a replacement for real leather. Imitation leather can be produced by bounding synthetic material to fabric surface. However, surface of imitation leather is mostly hydrophilic in nature which is not good for stain and water repellency. As a result, surface modification of imitation leather with rayon-flocked surface with organosilane by APP is studied in this paper. Organosilane is one of the monomers used for introducing hydrophobic surface, because of its stability and low toxicity $[7-10]$.

We use tetramethylsilane (TMS) in this study, together with APP treatment. In order to maximize the result, a detailed study of process parameters is required. The discharge power, amount of precursor applied and jet distance are the process parameters studied. After APP treatment, contact angle is used to evaluate the change in surface hydrophobicity, on being subjected to water, coffee and milk tea.

\footnotetext{
${ }^{*}$ Corresponding author. Tel.: +852-27666531; fax: +852-27731432

E-mail address: tccwk@polyu.edu.hk(C.W.Kan)
}

\section{EXPERIMENTAL}

\subsection{Material}

Imitation leather with rayon-flocked surface was supplied by Fifield (Asia) Ltd. It was produced by laminating $100 \%$ viscose rayon fabric with $100 \%$ viscose rayon short fibre to produce a flocked surface as shown in Fig. 1. The imitation leather was cut into size of width $1 \mathrm{~cm} \times 2.5 \mathrm{~cm}$ for APP treatment. The sample was stored in a conditioning room at $65 \pm 2 \%$ relatively humidity and $21 \pm 1{ }^{\circ} \mathrm{C}$ temperature for 24 hours prior to experiment.

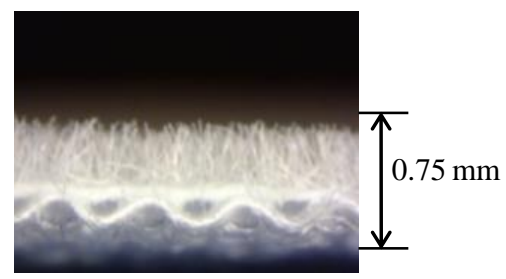

Fig. 1. Imitation leather with rayon-flocked surface

\subsection{Atmospheric pressure plasma (APP) treatment}

An atmospheric pressure plasma (APP) generator (a glow discharge plasma generator), Atomflo ${ }^{\mathrm{TM}}-400$ (Surfx Technology, US), was used for the APP treatment. Gas discharge was generated by applying a radio frequency of $13.56 \mathrm{MHz}$. The plasma beam geometry is $1 \mathrm{~mm} \times 25.4 \mathrm{~mm}$. Fig. 2 schematically shows the experimental set-up for APP treatment. Helium was used as the carrier gas and tetramethylsilane (TMS) (ACROS, $99 \%$ was applied as precursor. Various process parameters, i.e. discharge power $(120 \mathrm{~W}, 140 \mathrm{~W}, 160 \mathrm{~W}$ and $200 \mathrm{~W})$, amount of TMS $(0.075 \mathrm{ml}, 0.1 \mathrm{ml}, 0.125 \mathrm{ml}$, $0.150 \mathrm{ml}, 0.175 \mathrm{ml}, 0.2 \mathrm{ml}, 0.225 \mathrm{ml}, 0.25 \mathrm{ml}$ and $0.4 \mathrm{ml}$, the TMS was vapourised in a bubbler and per litre of helium) and jet-to-substrate distance $(10 \mathrm{~mm}, 15 \mathrm{~mm}$, $20 \mathrm{~mm}, 25 \mathrm{~mm}, 30 \mathrm{~mm}$ and $35 \mathrm{~mm}$ ) were used for fabricating the hydrophobic surface, in order to determine the ideal settings for maximum hydrophobicity. The 
helium flow rate was 30 litre per minute while the treatment time was 30 seconds.

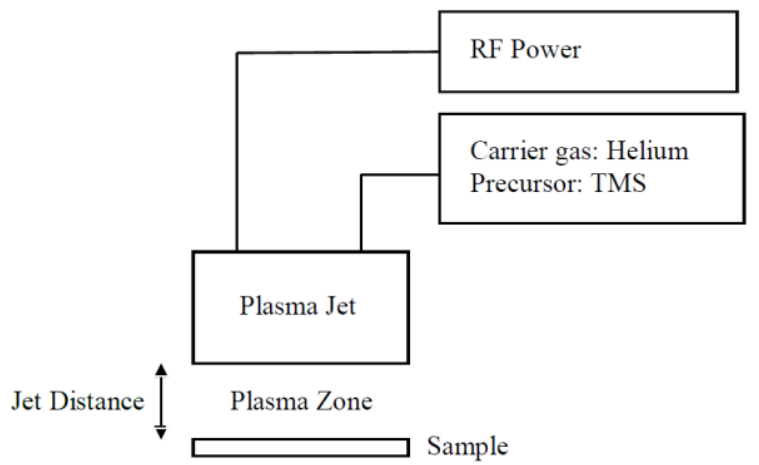

Fig. 2. Schematic diagram of APP treatment

\subsection{Contact angle}

The surface hydrophobicity was quantified by measurement of the sessile drop static contact angle with contact angle goniometer $[11,12]$. A drop of $5 \mu \mathrm{l}$ deionized water was used to probe the sample surface. The droplet images were recorded by a high-resolution camera. Five readings were taken from each sample and mean value of the readings was calculated. The measurement was done immediately after APP treatment. The greater the contact angle, the more the hydrophobicity of the sample will be. Contact angle of untreated sample is $0^{\circ}$ (i.e. the surface absorbs water immediately).

\subsection{Stain resistance}

Instant coffee (Nescafe, Premium white coffee, prepared by dissolving $35 \mathrm{~g}$ instant coffee power in $180 \mathrm{ml}$ distilled water $\left(25^{\circ} \mathrm{C}\right)$ at room temperature) and instant milk tea (Lipton, Gold Milk Tea, prepared by dissolving $16.5 \mathrm{~g}$ instant milk tea powder in $150 \mathrm{ml}$ distilled water $\left(25^{\circ} \mathrm{C}\right)$ at room temperature) were used for simulating the actual use condition when stain was placed on material surface. Coffee and milk tea are stain which are commonly found in daily use.

\section{RESULTS AND DISCUSSION}

\subsection{Effect of discharge power}

Fig. 3 shows contact angles of plasma treated samples as a function of discharge power. The discharge power used was in the range of $120 \mathrm{~W}$ to $200 \mathrm{~W}$. Experimental results show that $120 \mathrm{~W}$ gives the greatest $\mathrm{CA}$ value $\left(103^{\circ}\right)$ and after that the CA values gradually decrease to $95^{\circ}$ at $200 \mathrm{~W}$. Generally speaking, high discharge power may generate more plasma species to interact with the material surface. When more active plasma species are generated in the plasma zone, they may have higher chance to collide with each other which reduces the activity for the plasma treatment. In addition, at high discharge power, the temperature in the plasma jet becomes too high, leading to thermal degradation of imitation leather surface $[11,12]$. As a result, the contact angle values decrease gradually with increase of discharge power.

\subsection{Effect of amount of TMS}

Fig. 4 shows the CA values of plasma treated samples as a function of the amount of TMS used. It is obvious that no enhancement in CA is caused by increasing the amount of TMS from 0.075 to $0.125 \mathrm{ml}$.

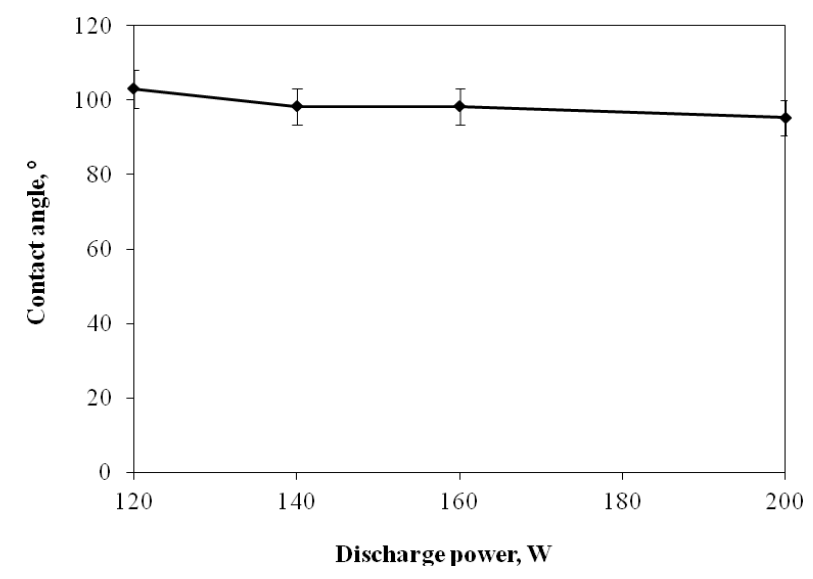

Fig. 3. Contact angle of plasma treated samples. Process parameters: amount of $\mathrm{TMS}=0.2 \mathrm{ml}$; jet distance $=10 \mathrm{~mm}$

Surface hydrophobicity of the sample starts increasing only after the amount of TMS deposited on the surface exceeds $0.125 \mathrm{ml}$ and it keeps increasing hydrophobicity until the amount of TMS reaches $0.2 \mathrm{ml}$. There is no further increase in CA values after that. Probably there is a maximum deposition of TMS because with an increase of TMS, the thickness of the TMS layer increases proportionally but from a certain thickness, the surface structure remains the same and so the hydrophobocity is also the same. On the other hand, the collisions between helium plasma species and TMS species increase in the plasma zone and therefore, fewer active TMS species can react with the imitation leather surface leading to no further increase in CA value [10, 13].

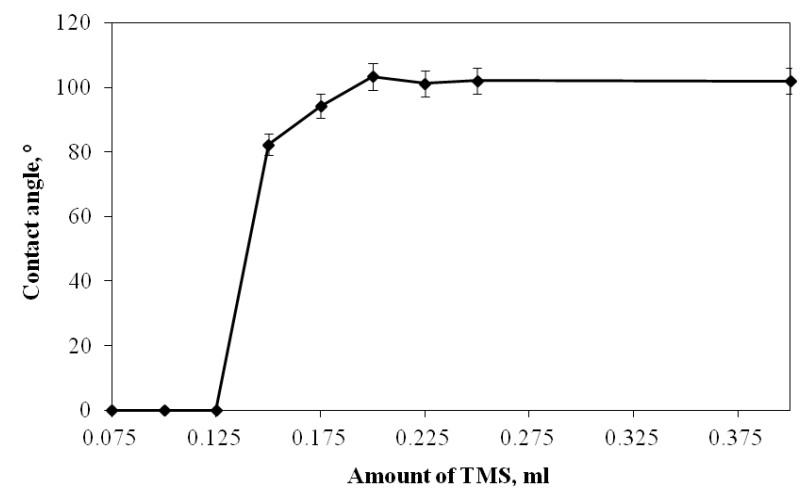

Fig. 4. Contact angle of plasma treated samples. Process parameters: discharge power $=120 \mathrm{~W}$; jet distance $=10 \mathrm{~mm}$

\subsection{Effect of jet distance}

Jet distance is defined as the distance that separates the plasma jet and the substrate surface. Fig. 5 shows the CA values of plasma treated sample as a function of the jet distance. The largest CA of about $103^{\circ}$ was achieved at separation of $10 \mathrm{~mm}$. Starting from $10 \mathrm{~mm}$ onwards, the larger is the separation, the smaller the CA is. It is because fewer active species can reach specimen surface after traveling a long separation which agrees with the short lifetime of active species from atmospheric pressure plasma [14]. In addition, when the jet distance increases, the velocity and activity of the active species in the plasma 
jet greatly decrease upon reaching the imitation leather surface and so the effectiveness of the surface reaction is not enough [15]. Meanwhile, too short a jet distance can result in thermal degradation of the specimen since the surface may melt under excessive heat developed in plasma jet $[11,12]$. Separation by less than $10 \mathrm{~mm}$ was not considered in this study.

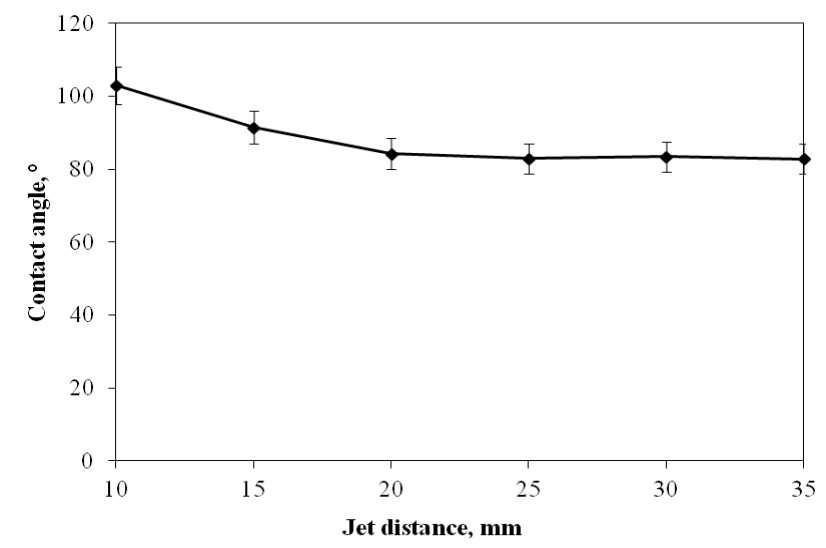

Fig. 5. Contact angle of plasma treated samples. Process parameters: discharge power $=120 \mathrm{~W}$; amount of TMS $=0.2 \mathrm{ml}$

\subsection{Stain resistance}

In this study, stain resistance properties of imitation leather with rayon-flocked surface was evaluated by testing resistance against coffee and milk tea. The greater the contact angle obtained with coffee and milk tea, the better is the stain resistance. Table 1 shows that there is a noticeable improvement in stain resistance to both coffee and milk tea after APP treatment with TMS. Before APP treatment, coffee and milk tea can be absorbed immediately (contact angle $=0^{\circ}$ ) by the imitation leather surface in which the surface gets wet completely. However, the APP treatment increases the surface hydrophobicity in relation to the increase in CA values. As a result, APP treatment with TMS introduces stain resistance effect to imitation leather with rayon-flocked surface.

Table 1. CA of different liquids (treatment parameter: discharge power $=120 \mathrm{~W}, \quad$ amount of TMS $=0.2 \mathrm{ml}$, jet distance $=10 \mathrm{~mm}$, treatment time $=30 \mathrm{~s}$ )

\begin{tabular}{|l|c|c|}
\hline Liquid & Untreated & APP Treated \\
\hline Deionised Water & 0 & $103 \pm 2^{\circ}$ \\
\hline Coffee & 0 & $96 \pm 2^{\circ}$ \\
\hline Milk Tea & 0 & $90 \pm 2^{\circ}$ \\
\hline
\end{tabular}

\section{CONCLUSIONS}

The hydrophobicity of imitation leather with rayonflocked fabric is greatly enhanced by atmospheric plasma treatment with TMS $(0.2 \mathrm{ml})$. The process parameters were the key factors affecting the final results. In this study, adequate discharge power $(120 \mathrm{~W})$ was required to maintain good plasma discharge. A jet distance of $10 \mathrm{~mm}$ is suggested for allowing the plasma species to react with the material surface. With the optimum process parameters, a highly hydrophobic surface can be obtained, with good resistance to deionised water, coffee and milk tea.

\section{Acknowledgement}

Authors would like to thank the financial support from the Hong Kong Polytechnic University for this work.

\section{REFERENCES}

1. Shang, M.H., Wang, Y., Limmer, S.J., Chou, T.P., Takahashi, K., Cao, G.Z. Optically Transparent Superhydrophobic Silica-Based Films Thin Solid Films 472 2005: pp. $37-43$. http://dx.doi.org/10.1016/j.tsf.2004.06.087

2. Huang, L., Lau, S.P., Yang, H.Y., Leong, E.S.P., Yu, S.F., Prawer, S. Stable Superhydrophobic Surface via Carbon Nanotubes Coated with a ZnO Thin Film Journal of Physical Chemistry B 109 2005: pp. 7746-7748. http://dx.doi.org/10.1021/jp046549s

3. Lee, H.J., Michielsen, S. Preparation of a Superhydrophobic Rough Surface Journal of Polymer Science: Part B: Polymer Physics 45 2007: pp. 253-261. http://dx.doi.org/10.1002/polb.21036

4. Kim, S.H., Kim, J., Kang, B., Uhm, H. Superhydrophobic CFx Coating via In-line Atmospheric RF Plasma of $\mathrm{He}_{-} \mathrm{CF}_{4}-\mathrm{H}_{2}$ Langmuir 21 2005: pp. 12213-12217.

5. Tsougeni, K., $\quad$ Vourdas, N., Tserepi, A., Gogolides, E. Mechanisms of Oxygen Plasma Nanotexturing of Organic Polymer Surfaces: From Stable Super Hydrophilic to Super Hydrophobic Surfaces Langmuir 25 2009: pp. $11748-11759$.

6. Raballand, V., Benedikt, J., von Keudell, A. Deposition of Carbon-free Silicon Dioxide from Pure Hexamethyldisiloxane Using an Atmospheric Microplasma Jet Applied Physics Letters 92 2008: pp. 091502.

7. Fonseca, J.L.C., Apperley, D.C., Badyal, J.P.S. Plasma Polymerization of Tetramethylsilane Chemistry of Materials 5 1993: pp. 1676-1682.

8. Favia, P., Lamendola, R., d'Agostino, R. The Role of Substrate Temperature and Bias in the Plasma Deposition from Tetramethylsilane Plasma Sources Science and Technology 1 1992: pp. 59-68.

9. Fonseca, J.L.C., Tasker, S., Apperley, D.C., Badyal, J.P.S. Plasma-Enhanced Chemical Vapor Deposition of Organosilicon Materials: A Comparison of Hexamethyldisilane and Tetramethylsilane Precursors Macromolecules 29 1996: pp. $1705-1710$.

10. Park, S.Y., Kim, H., Hong, S.U., Sasabe, H. Plasma Polymerization of Hexamethyldisilazane Polymer Journal 22 1990: pp. 242-249.

11. Kwong, C.H., Ng, S.P., Kan, C.W., Molina, R. Parametric Study of $\mathrm{CF}_{4}$-plasma on the Hydrophobicity of Polyester Synthetic Leather Fibers and Polymers 14 2013: pp. $1608-1613$.

12. Kwong, C.H., Ng, S.P., Kan, C.W., Molina, R. Inducing Hydrophobic Surface on Polyurethane Synthetic Leather by Atmospheric Pressure Plasma Fibers and Polymers 15 2014: pp. $1596-1600$.

13. Kan, C.W., Yuen, C.W.M. Effect of Atmospheric Pressure Plasma Treatment on Wettability and Dryability of Synthetic Textile Fibres Surface and Coatings Technology 228(S1) 2013: pp. S607-S610.

14. Wang, C.X., Qiu, Y.P. Two Sided Modification of Wool Fabrics by Atmospheric Pressure Plasma Jet: Influence of Processing Parameters on Plasma Penetration Surface and Coatings Technology 201 2007: pp. 6273-6277.

15. Rakowski, W. Plasma Treatment of Wool Today. Part 1 - Fibre Properties, Spinning and Shrinkproofing Journal of Society of Dyers and Colourists 113 1997: pp. 250-255. http://dx.doi.org/10.1111/j.1478-4408.1997.tb01909.x 